\title{
Occurrence and significance of copepod resting egg accumulation in seagrass sediments
}

\author{
Lindsay P. Scheef ${ }^{1, *}$, Nancy H. Marcus $^{2}$ \\ ${ }^{1}$ Department of Oceanography and ${ }^{2}$ The Graduate School, Florida State University, Tallahassee, Florida 32306, USA
}

\begin{abstract}
The resting eggs produced by some species of marine calanoid copepods have been observed to accumulate on the seafloor in areas of high deposition and low resuspension. Seagrass beds are known to be environments that promote the accumulation of fine sestonic particles by inhibiting resuspension but have not been previously investigated as possible reservoirs for copepod resting eggs. Field sampling on a shallow reef in the northern Gulf of Mexico over 3 yr revealed that viable resting eggs of the copepod Acartia tonsa were significantly more abundant in seagrass-colonized sediment than in adjacent unvegetated sediment. Egg abundance differences between the 2 environment types occurred throughout each year. Differences tended to be greatest during the summer when the seagrass canopy was highest. These results suggest that the unique effects seagrass blades and rhizomes have on sediment stabilization may make seagrass beds important accumulation sites for resting copepod eggs in shallow areas subject to frequent disturbance. Seagrass-mediated resuspension events could therefore influence the population dynamics of some copepod species and may be essential for local copepod populations reliant on recruitment from benthic eggs. The effects that seagrass presence may have on the benthic distribution of resting stages produced by other species of zooplankton and phytoplankton should be evaluated, and the possible effects of resting stage accumulation in seagrass on plankton communities and whole ecosystems should be considered.
\end{abstract}

KEY WORDS: Copepod dormancy $\cdot$ Resting eggs $\cdot$ Particle trapping $\cdot$ Resuspension $\cdot$ Seagrass

\section{INTRODUCTION}

Zooplankton such as copepods are a vital link at the base of many coastal food webs (e.g. Turner 2004). While these organisms are often considered to be holoplankton, plankton that spend their entire lives in the water column, many species of zooplankton are capable of incorporating a benthic phase into their life cycle by producing cysts or eggs that sink to the sea bottom and remain viable in the sediment (Marcus \& Boero 1998). At least 49 species of estuarine or marine calanoid copepods are capable of producing fertilized eggs which, after being spawned by females and settling through the water column, can remain dormant as 'resting eggs' in the benthic environment until they experience appropriate hatching conditions (see Engel \& Hirche 2004).
Initial studies identified at least 2 types of resting eggs (Grice \& Marcus 1981). 'Subitaneous' eggs may hatch immediately after development but will become quiescent under unfavorable hatching conditions. 'Diapause' eggs must remain dormant for a refractory phase before they have the potential to hatch under suitable conditions. More recently, Chen \& Marcus (1997) found evidence of a third type of egg, described as delayed-hatching eggs, which hatch gradually over an extended period of time.

High numbers of copepod resting eggs observed in freshwater and marine sediments of seasonally influenced regions suggest that they are an important part of the copepod life cycle (Marcus \& Lutz 1998, Engel \& Hirche 2004). By producing resting eggs, copepod populations can survive unfavorable fluctuations in salinity (Hall \& Burns 2001), temperature (Marcus 
1989, Viitasalo 1992), predation pressure (Lass \& Spaak 2003), or algal food concentration (Ban \& Minoda 1992, Viitasalo 1992), during which some species may completely disappear from the water column and resume activity when suitable conditions return.

It is important to identify areas where resting eggs accumulate, because spatial variations in their benthic abundance can influence the distribution and abundance of pelagic copepod populations (Lindley 1990, Marcus 1996). Copepod resting eggs behave as sediment particles in the water column and tend to accumulate in areas where other fine particles settle (Marcus \& Fuller 1989, Lindley 1990). Once buried in the sediment, the eggs are reliant on physical or biological disturbances to resuspend them in the water column or return them to the sediment surface where they have the opportunity to hatch (Viitasalo 1992). Factors that influence benthic-pelagic coupling may therefore play an important role in the population dynamics of copepod species that produce resting eggs.

Seagrass beds are known to regulate benthicpelagic processes such as nutrient cycling (e.g. McGlathery et al. 2007), suspension of settled particulate matter (e.g. van der Heide et al. 2007), and settlement of the larvae of benthic organisms (e.g. Boström \& Bonsdorff 2000), but no consideration has been given to how seagrass presence may influence the interactions between zooplankton populations and their benthic resting stages. Seagrass beds significantly inhibit the resuspension of particles, and in some cases, enhance their deposition (Gacia et al. 1999, Agawin \& Duarte 2002). Seagrass blades baffle currents, raising the zone of high vertical shear usually observed just above the bottom in unvegetated areas to a height where it has less influence on the sediment surface (Gambi et al. 1990). This allows finer particles to become trapped in the bed when they would otherwise be resuspended and removed by water flow (Granata et al. 2001). Although numerous studies have examined the accumulation of particles in seagrass beds, few have focused on particle types (Duarte et al. 1999). It is possible that copepod eggs are included among these finer particles and that the presence of seagrass affects their distribution.

To date, no studies have examined whether the presence of seagrass affects the benthic distribution of marine copepod resting eggs. Studies examining the benthic distribution of resting eggs in marine environments have not made note of the presence or absence of seagrass, and studies examining particle flux within seagrass beds have not made note of resting eggs as contributors. It is possible that seagrass beds serve as reservoirs for copepod eggs, allowing large numbers to accumulate and periodically releasing them into the water column during storm events or seasons when seagrass blades die off.

The purpose of this study was therefore to determine the concentrations of viable calanoid copepod eggs in seagrass beds and compare them to concentrations in unvegetated areas. The benthic distribution of eggs could be influenced by a variety of biological (e.g. bioturbation), physical (e.g. grass blade height), and chemical (e.g. oxygen levels) factors, so regular field sampling over 3 yr was conducted to account for possible seasonal fluctuations in suspected influencing factors.

\section{MATERIALS AND METHODS}

Study location and species of focus. Lanark Reef $\left(29^{\circ} 53^{\prime} \mathrm{N}, 84^{\circ} 33^{\prime} \mathrm{W}\right)$ is a $6.5 \mathrm{~km}$ long shoal running parallel to the coast of the Florida panhandle (Fig. 1). This site was chosen because of its proximity to the Florida State University (FSU) Coastal and Marine Laboratory at Turkey Point, its composition of large sandy areas spotted with patches of seagrass, and its consistent exposure to turbulent water conditions due to its shallow depth $(\sim 1 \mathrm{~m}$ at high tide). While a substantial proportion of the subtidal sediment at Turkey Point, Florida, is 2 to $3 \mathrm{~m}$ deep and covered with a fairly continuous mix of Thalassia testudinum (turtle grass) and Syringodium filiforme (manatee grass; Iverson \& Bittaker 1986), the patches of seagrass on Lanark Reef are primarily composed of the robust species Halodule wrightii (shoal grass) because the reef is shallower than the surrounding area and experiences greater wave exposure. All field samples were obtained at this location.

The resting eggs of several calanoid copepod species have been found in the sediments along the Florida panhandle (Marcus 1989, Chen \& Marcus 1997). Eggs of Acartia tonsa were chosen as the focus in this study because preliminary sampling revealed a significantly higher abundance of their eggs relative to those of other local species. Also, in this area $A$. tonsa is present in the water column year-round and is not believed to produce diapause eggs (Chen \& Marcus 1997), so there was little risk of overlooking viable eggs in a refractory phase during sample processing. The subitaneous eggs of $A$. tonsa from this region are capable of surviving from a few days up to $1 \mathrm{mo}$ in the sediment (Marcus \& Lutz 1994, Marcus et al. 1997) but are able to develop and hatch within $24 \mathrm{~h}$ if exposed to appropriate ambient conditions (pers. obs.).

Station selection. Along the northeast edge of Lanark Reef, 5 Stns (Fig. 1) were sampled on each sam- 


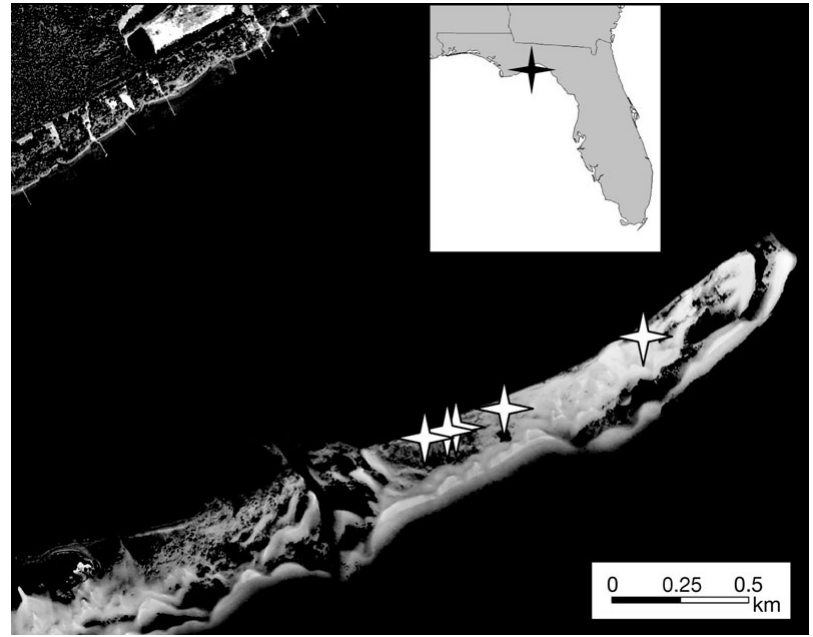

Fig. 1. Lanark Reef. Locations of the 5 stations randomly selected for the regular sampling of benthic egg abundance. The coordinates of the stations, from west to east, are: $29^{\circ} 52.924^{\prime} \mathrm{N}, \quad 84^{\circ} 33.326^{\prime} \mathrm{W}$; $\quad 2^{\circ} 52.492^{\prime} \mathrm{N}, \quad 84^{\circ} 33.280^{\prime} \mathrm{W}$; $29^{\circ} 52.952^{\prime} \mathrm{N}, \quad 84^{\circ} 33.271^{\prime} \mathrm{W}_{\mathrm{i}} \quad 2^{\circ} 52.981^{\prime} \mathrm{N}, \quad 84^{\circ} 33.140^{\prime} \mathrm{W}$; $29^{\circ} 53.122^{\prime} \mathrm{N}, 84^{\circ} 32.820^{\prime} \mathrm{W}$

pling date to determine benthic egg abundance. Each station was considered a replicate and consisted of 2 substations: a patch of seagrass and a large adjacent sandy area. Stations were selected by marking 30 different grass patches of at least 2 m diameter as way points on a handheld Garmin GPSMAP $76 \mathrm{~S}$ unit and choosing 5 using a random number table. The seagrass patch at each station was marked with a 1 inch PVC pipe extending $\sim 30 \mathrm{~cm}$ above the sediment surface.

Sediment sampling. From September 2005 through September 2008, 2 cores were taken approximately monthly from each of the 5 selected seagrass patches along with 2 from each adjacent sandy area (referred to as 'grass' or 'sand' samples). Each set of 2 cores from a substation (sand or seagrass) was considered a 'pair' and ultimately treated as 1 sample for data analysis. Each core was obtained using a $4.8 \mathrm{~cm}$ inner diameter tube that was inserted by hand in the seabed to a depth of $\sim 10$ to $15 \mathrm{~cm}$, capped, and removed. Care was taken to ensure that the top $2 \mathrm{~cm}$ of sediment were intact and relatively undisturbed within the core. Sediment cores were transferred to an insulated chest for transport to the FSU main campus.

Core processing and viable egg determination. Core samples were transported to the laboratory and stored overnight at $23.5 \pm 0.5^{\circ} \mathrm{C}$. The next morning, water was removed from the top of the core tubes with a handheld pump and checked for nauplii. The cores became dark in color and smelled of sulfide shortly after sampling, and in these presumably anoxic condi- tions very few nauplii hatched between sampling and processing.

A whole sediment incubation method was chosen to estimate viable egg abundance in the samples, because preliminary experiments had revealed that the centrifugation associated with the sugar flotation method of extracting zooplankton eggs from sediment (Onbé 1978) significantly reduced the viability of Acartia tonsa subitaneous eggs (unpubl. data). The upper $2 \mathrm{~cm}$ of sediment were individually sliced from each core through the use of a core extruder. Each slice was divided in half to yield a total of 4 halves depth ${ }^{-1}$ for each core pair. Each half slice was placed in a Petri dish and mixed with seawater that had been passed through a filter bag with a $1 \mu \mathrm{m}$ rating to allow hatching.

From September 2005 through September 2006, each of the 4 sediment slice halves was assigned to 1 of 4 treatments designed by varying incubation salinities and temperatures to test for variable hatch patterns under different conditions. However, hatch patterns and species compositions were similar regardless of incubation conditions (unpubl. data), so as of October 2006, all core segments were assigned to the same treatment to increase sample size.

Each half slice was placed in its own Petri dish to allow the sediment to spread to $\sim 2 \mathrm{~mm}$ deep to encourage hatch by increasing the probability of eggs being exposed to well oxygenated conditions. The incubation therefore contained a total of 80 dishes: $10 \times 4$ halved slices of 'grass' and 'sand' cores. All dishes were filled to $1 \mathrm{~cm}$ depth with $30 \%$ (measured with a Reichert Brix handheld refractometer) $1 \mu \mathrm{m}$ bag-filtered seawater and placed into an incubator set at $23.5 \pm 0.5^{\circ} \mathrm{C}, 13 \mathrm{~h}$ light:11 h dark.

Hatched nauplii were removed from each dish and counted at $24 \mathrm{~h}$ intervals by decanting the water above the sediment in a dish through a $50 \mu \mathrm{m}$ mesh and rinsing the contents of the mesh into a well assigned to the dish. Swimming nauplii in each well were counted under a dissecting microscope. After enumeration, the nauplii were either discarded or raised to adulthood (see below), and the sediment samples in the incubation dishes were covered with fresh, bag-filtered seawater as described above. The dishes were monitored daily until the number of hatching nauplii neared zero (about 3 to $5 \mathrm{~d}$ ), and the total numbers of nauplii were considered as estimates of the total numbers of viable eggs present. Hatch numbers from each set of 4 dishes representing a $1 \mathrm{~cm}$ slice of a pair of cores were combined and considered 1 replicate.

At the beginning of the study, the hatched nauplii were stored in a beaker and fed the dinoflagellate Prorocentrum micans to rear them for eventual identification. This revealed that the vast majority of copepods 
hatched from the sediment were Acartia tonsa. Other copepods identified were benthic harpacticoid species and the summer calanoid species Labidocera aestiva. The nauplii of these copepods were distinct from $A$. tonsa nauplii, so this analysis was deemed unnecessary after the first year of sampling.

Field condition measurements. Environmental characteristics measured in the field included water temperature, salinity, and depth as well as seagrass canopy height and stem density. The temperature and salinity of water on the reef were measured once during each sampling trip with a thermometer and Reichert Brix handheld refractometer, respectively, and approximate water depth and seagrass height were measured with a meter stick at each coring station. Grass stem density was determined for each station on 2 occasions by counting and averaging the numbers of grass stems in 8 sections of a randomly placed square meter grid of $10 \times 10 \mathrm{~cm}$ squares

Statistics. All egg abundance data were square-root transformed prior to statistical analysis. Since the same 5 stations were sampled repeatedly, the assumption could not be made that samples taken on each date were independent from those taken on other dates. To determine whether there was an overall significant difference in viable egg abundance between sand and grass environment samples, a repeated-measures ANOVA testing environment as a between-subjects factor was used. For this test, each sampling date represented an individual treatment, and each environment at each station represented a subject. A oneway ANOVA was used to test for a significant difference in egg abundance between environments on each individual date. One-way ANOVAs were used to test whether stations significantly differed in average depth, average grass length, average grass density, or average egg abundance. All tests were performed with SPSS Statistics 17.0 software.

\section{RESULTS}

\section{Egg hatch from core samples}

Overall, the average abundance of viable subitaneous Acartia tonsa eggs between sampling dates was highly variable and ranged from $44755 \pm 13548$ to $461 \pm 632$ eggs $\mathrm{m}^{-2}$. The most obvious temporal trend was low abundance during the winter months. There appeared to be 2 annual peaks in abundance during warmer seasons, which, however, were not consistent from year to year.

There were always higher numbers of viable eggs in the seagrass beds than in the adjacent sandy areas (Fig. 2). The amount of difference between abundance in each habitat varied greatly by date and ranged from nearly zero to over 30000 eggs $\mathrm{m}^{-2}$. Despite this high variability, statistics suggest that the difference in egg abundance between seagrass and bare sand is significant overall (repeated-measures ANOVA; p < 0.01) and for several of the individual sampling dates (oneway ANOVAs; $\mathrm{p}<0.05$ ). The high abundance of eggs in the seagrass patches combined with the presence of the deeper seagrass bed surrounding the reef indicate that most of the benthic copepod eggs in the study area are contained within seagrass-colonized sediments.

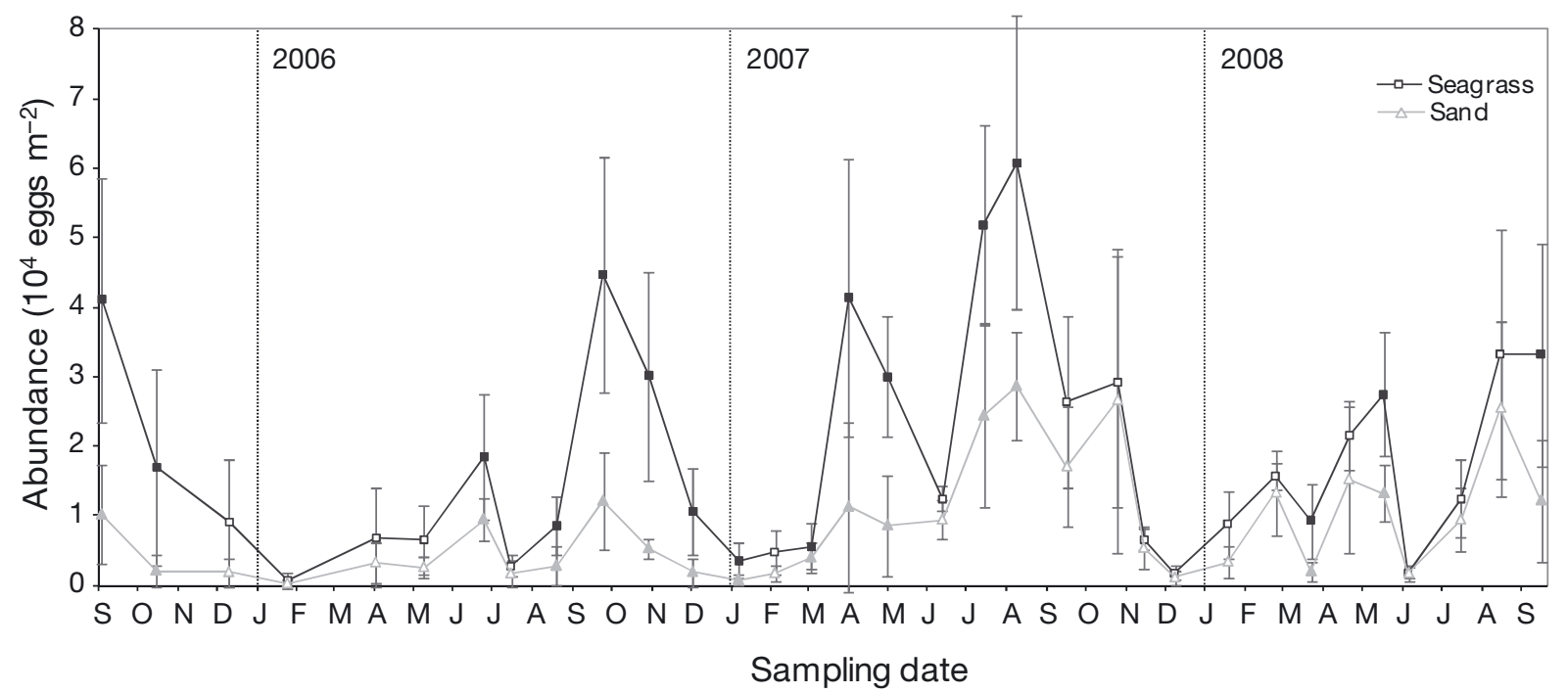

Fig. 2. Acartia tonsa. Subitaneous egg abundance in seagrass ( - -) and bare sand $\left(\bullet_{-}\right)$sediments from Lanark Reef as determined by nauplii hatch. Filled symbols: dates on which the difference between environments was significant $(p<0.05)$. Values are means $\pm 1 \mathrm{SD}$ 


\section{Field conditions}

Water salinity, water temperature, and seagrass height varied among sampling months and years. Salinity varied between 29 and $36 \%$, with no obvious seasonal trends, but was notably lower overall in 2005 and 2006 compared to 2006 and 2007 (Fig. 3a). In contrast, water temperature (Fig. 3b) and grass height (Fig. 3c) exhibited seasonal trends with high summer values and low winter values.

The average depth of the 5 stations measured during sampling was $0.52 \mathrm{~m}$ and ranged from $1 \mathrm{~m}$ to nearly zero, depending on tidal height and wind direction. Sampling was usually done at low tide, so the true average depth at the stations probably approached $0.75 \mathrm{~m}$. The depth between the seagrass patches and the bare sand at each station always differed, with the bare sand being an average of $0.1 \mathrm{~m}$ deeper than the seagrass patches.
Average grass stem density among the 5 sampling stations was determined to be $1675 \pm 343$ stems $\mathrm{m}^{-2}$ in August 2006 and $2113 \pm 451$ stems $\mathrm{m}^{-2}$ in February 2007. The difference between these 2 estimates is not significant (single-factor ANOVA, p > 0.05).

The 5 sampling stations did not differ in average egg abundance, grass length, water depth, or stem density (one-way multivariate ANOVA, p > 0.05).

\section{DISCUSSION}

Regular benthic sampling of a shallow, high energy reef along the Florida panhandle revealed that significantly higher abundances of subitaneous eggs produced by the copepod Acartia tonsa were present in patches of the seagrass Halodule wrightii than in adjacent unvegetated sediments. Although egg abundance was consistently greater in the seagrass sediments, the
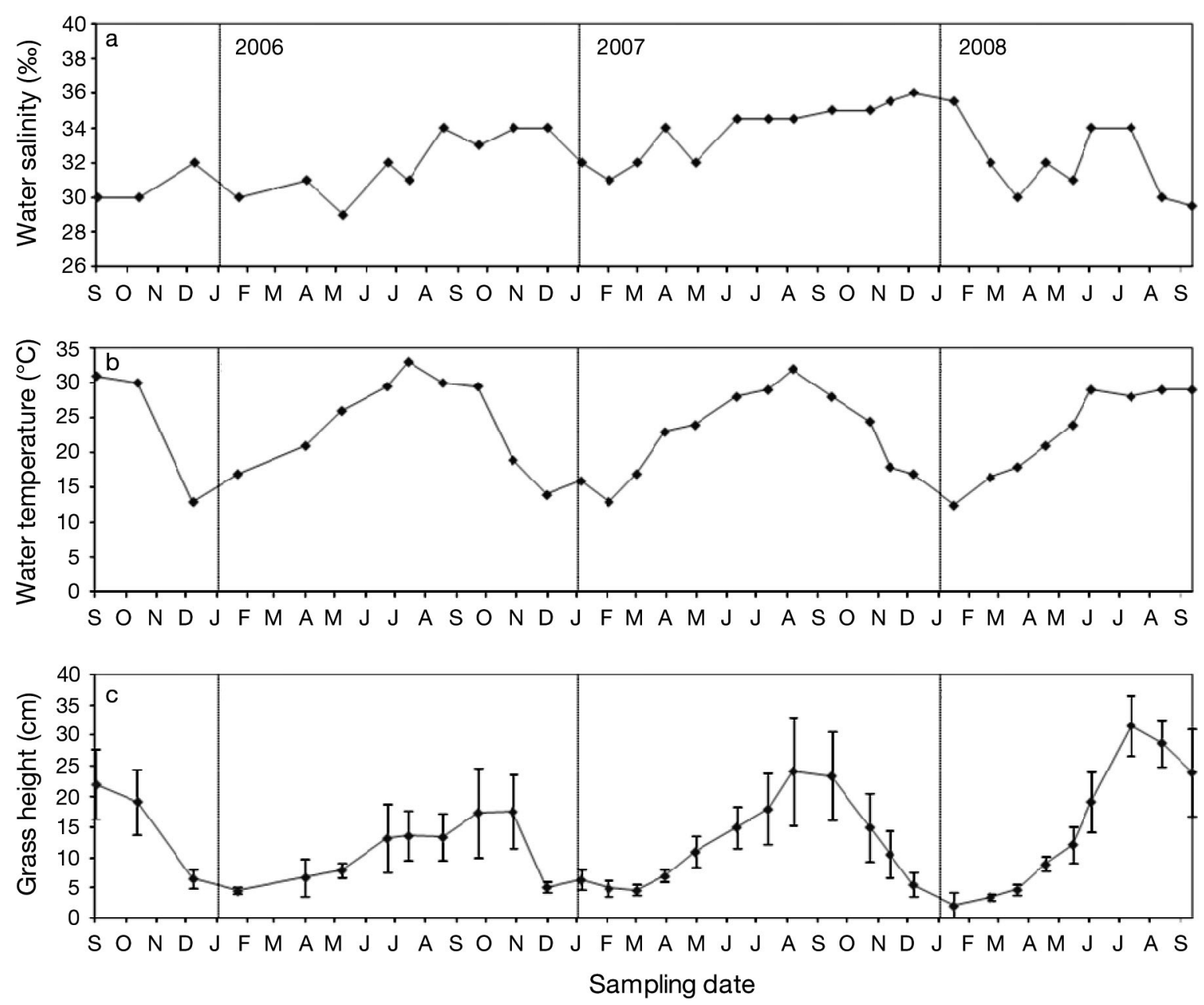

Fig. 3. Field conditions measured during benthic core sampling: (a) water salinity, (b) water temperature, (c) seagrass height; values are means $\pm 1 \mathrm{SD}$ 
amount of difference between environments varied over time and tended to be significant during warmer months. Several factors may have contributed to these observed patterns in benthic egg distribution.

During the summer months, the seagrass canopies of the Halodule wrightii patches on the reef were present and offered some protection to settled eggs and other fine organic particles from disturbance-related resuspension (Scheef 2010). Since the sampling site was a shallow, wave-influenced reef surrounded by deeper water, it is likely the copepod eggs present on the reef were subjected to a persistent cycle of settlement and resuspension caused by turbulence until they hatched or were transported to the deeper surrounding area. While eggs and fine particles settling on bare sediment would have been susceptible to immediate resuspension and removal by ambient currents and turbulence, eggs settling among seagrass blades would have experienced dampened water motion along with lower resuspension (Granata et al. 2001, Scheef 2010). Also, copepod eggs will not hatch while buried or exposed to low oxygen or anoxic conditions (Uye et al. 1979), so low oxygen conditions promoted by the decay of accumulated organic material and burial by the bioturbation of benthic macrofauna are likely to have acted in combination with the physical protection provided by the grass blades to promote egg accumulation in the seagrass patches (Scheef 2010).

Significant differences in egg abundance between seagrass and bare sand environments occurred less frequently during winter months (Fig. 2). During the winter, the absence of the seagrass canopy would have reduced the physical trapping ability of the seagrass patches (Gacia \& Duarte 2001), and cooler temperatures along with less trapped organic material within the seagrass patches would have promoted lower microbial activity (Thamdrup et al. 1998, Pringault et al. 2008) and more similar oxygen conditions between the sediment of both environments. However, some degree of enhanced egg accumulation in seagrass patches still appears to have occurred.

Despite the dying back of the seagrass blades during cooler months, the stems and rhizome mats of the seagrass patches remained intact. It was observed during this time that ripples would often form in the bare sand but not in the seagrass patches, so it appears that the presence of these structures may have maintained greater sediment stability in the seagrass patches than in the bare sand (Scheef 2010). This enhanced stability combined with egg burial through macrofaunal bioturbation could account for the winter abundance differences observed between environments. Micro-depositional zones created by water flow around the seagrass stems (Nepf et al. 1997) and sticky biofilms generated by algal mat growth on seagrass sediments (Fisher 2003, de Boer 2007) may have also contributed to the enhancement of egg accumulation in this environment during winter months.

\section{Significance of egg accumulation in seagrass beds}

Subitaneous and diapause copepod resting eggs have relatively slow sinking velocities and tend to settle with fine particles in calm areas (Marcus \& Fuller 1986). These accumulation locations are usually sheltered or deep enough to be protected from physical disturbances that could resuspend them (Marcus \& Boero 1998), and resting eggs that become buried in these locations are therefore reliant on relatively rare physical resuspension events or bioturbative activity for their return to the sediment surface where they may hatch (Marcus 1984). Seagrass beds, however, are shallow-water features exposed to current flow and relatively frequent storm disturbance. Seagrass beds therefore represent a unique egg accumulation environment, and eggs that settle within them may play different roles in the dynamics of the pelagic population than resting eggs that settle elsewhere.

The resting eggs of copepods have been described as serving several functions that ultimately contribute to the sustainability of the pelagic population. The diapause eggs of marine calanoid copepods, which are believed to be capable of surviving multiple months to several years in the sediment (Marcus \& Lutz 1998), have been associated with the seasonal recruitment of nauplii and with the possible formation of 'egg banks.' The possible roles that short-lived subitaneous resting eggs may play in the population dynamics of planktonic copepods are less clear (Marcus 1996), although high densities in the sediments of some areas suggest they are important to the persistence of some populations (e.g. Katajisto et al. 1998). The longevity of this egg type is reported to vary from several days to a few months (Marcus \& Lutz 1998), although in some cases cool temperatures may extend viability past 1 yr (Katajisto 2004). It has been suggested that large numbers of subitaneous eggs in the sediment may result in a more constant pelagic population by providing time-released recruitment into the plankton (Uye 1985, Katajisto et al. 1998). Such time-released recruitment may also allow a 'sampling' of different conditions in a highly variable environment (De Stasio 1990, Chen \& Marcus 1997). The short-term viability of subitaneous eggs implies that significant mortality could occur if benthic disturbance and resuspension at accumulation sites are infrequent. Seagrass beds which occur in relatively 
shallow water susceptible to wave disturbance may therefore represent more advantageous accumulation sites for subitaneous copepod eggs than calm, protected areas.

In seagrass beds, mild to moderate waves and currents are attenuated by the presence of the canopy, so the shear stress threshold where resuspension and erosion of sediment will occur is not reached as readily as in unvegetated areas (van der Heide et al. 2007). Therefore, during periods of calm to moderate water flow, subitaneous eggs could be expected to gradually accumulate within seagrass sediments up to the point of a disturbance where the resuspension threshold is exceeded. Within the timeframe of the subitaneous eggs' lifespan, waves produced by strong winds could be expected to promote large-scale resuspension (Scheef 2010) and subsequent hatch of eggs accumulated within seagrass beds, providing a pulse of individuals to the pelagic population.

These turbulence-triggered pulses of hatch may ensure that a large number of copepod individuals are present in the water column during the formation of phytoplankton blooms stimulated by storm-generated nutrient resuspension (Asmus \& Asmus 2000, Lawrence et al. 2004) and runoff (Hoover et al. 2006). This synchronization would allow the copepod population to more efficiently exploit the increase in food abundance and may control the amount of phytoplankton biomass in the water column (Yin et al. 1996, Tsuda et al. 2007). Control of algal biomass would be beneficial to seagrass by maintaining water column clarity and high light penetration.

Pulses of subitaneous egg hatch from seagrass beds could also be advantageous to pelagic copepod populations under heavy predation pressure. Invertebrate predation on small copepods can be very high (Baier \& Purcell 1997, Eiane et al. 2002) and post-hatch mortality has great potential to limit the size of copepod populations (Kiørboe 1997). Lags in predator response to sudden increases in their zooplankton grazer prey have been observed (Roman et al. 1995, Hoover et al. 2006), so a sudden and dramatic increase in the number of copepods in the water column after a resuspension event may overwhelm predators and allow the population to temporarily increase in size.

\section{Applicability: other seagrass ecosystems}

The maximum egg abundances observed in seagrass patches during this study are 2 orders of magnitude lower than maximum abundances observed in deeper or more sheltered areas (e.g. Katajisto et al. 1998). However, the efficiency of water motion reduction that inhibits resuspension in seagrass beds can depend on seagrass species, canopy height, seagrass density, and hydrodynamic regime. The patches of seagrass that were the focus of this study are likely to have represented minimal effects of seagrass on egg accumulation with significant results; other systems may have significantly higher retention efficiencies.

Halodule wrightii is a seagrass species that often occurs in highly disturbed areas where small particle accumulation is less likely to occur, owing to frequent flow penetration into the canopy (van Keulen \& Borowitzka 2003, Di Carlo \& Kenworthy 2008), and such was the case in the present study. The stem densities measured in this study are much lower than $H$. wrightii stem densities measured in other areas (Green \& Short 2003). Also, the blades of $H$. wrightii are much narrower than the blades of other common species such as Zostera spp., Posidonia spp., and Thalassia spp., and these wider-bladed species can reach well over twice the $30 \mathrm{~cm}$ maximum length measured for $H$. wrightii in this study (Green \& Short 2003). Leaf area is thought to be an important factor contributing to the particle trapping ability of seagrass (Gacia et al. 1999), so between the low stem density, short blade length, and narrow blade width of the $H$. wrightii in the present study, similar or more dramatic egg accumulation could be expected to occur in other systems.

\section{Applicability: other resting stages}

The subitaneous and diapause eggs released by copepod species other than Acartia tonsa can be expected to have similar settling velocities and benthic distribution patterns owing to their relatively small sizes and low densities (Marcus \& Fuller 1986) and are therefore also likely to accumulate in seagrass beds. For diapause eggs capable of surviving burial over seasons or years (e.g. Marcus \& Lutz 1998), long-term resuspension patterns within seagrass beds may become important for their return to the sediment surface where they may have the opportunity to hatch.

In coastal areas that experience strong seasonal change, winter dieback of seagrass canopies allows resuspension of sediment within the beds to increase (Gacia \& Duarte 2001), so materials within the sediment protected from resuspension by the canopy in the preceding season may be released. This type of seasonally regulated resuspension pattern may be advantageous to copepod species that survive disappearance from the water column during summer by producing diapause eggs cued to hatch by the same conditions which cause seagrass dieback.

It is likely that bioturbation within seagrass beds would lead to the formation of a layer of diapause eggs below the depth of frequent or seasonal sediment 
resuspension (Viitasalo 1992). Over time scales of multiple years or decades, diapause eggs accumulated at depth in the sediment can become egg banks that may serve to maintain genetic diversity in the population over time or aid in its recovery after dramatic environmental change (Hairston 1996, Hairston \& Kearns 2002). In most calm depositional environments, eggs within deep sediment layers would primarily be dependent on bioturbation for return to the surface (Marcus 1984), but in seagrass beds various processes aside from bioturbation could exhume deeply buried eggs.

Storm events such as hurricanes can cause extensive sediment movement and rhizosphere erosion within seagrass beds (e.g. Hammerstrom et al. 2006), and various types of disturbance promote regular cycles of vegetation gap formation inside seagrass beds (Bell et al. 1999). The migration of bedforms or subaqueous dunes in areas colonized by quick-growing seagrass can also lead to consistent patterns of seagrass bed growth and erosion (Marbà \& Duarte 1995). These processes may promote regular hatching of nauplii from deeply buried diapause egg banks within seagrass beds.

The unique conditions and processes within seagrass beds that allow for the accumulation, retention, and both abrupt and gradual release of subitaneous and diapause copepod resting eggs are likely to affect the resting stages produced by other organisms. The formation of seed banks within seagrass beds due to the retention of seeds produced by the plants themselves has been recognized as an important feature of some seagrass species which allows them to recover after disturbances and mass mortality events (Hammerstrom et al. 2006, Lee et al. 2007). In addition to copepods, other planktonic organisms such as rotifers, tintinnids, cnidarians, cladocerans, dinoflagellates, and diatoms have been reported to produce resting stages that accumulate as fine particles in sediments and may be important parts of their life cycles (McQuoid \& Hobson 1996, Marcus \& Boero 1998, Joyce 2004).

\section{CONCLUSIONS}

Seagrass beds are known to influence coastal benthic-pelagic processes such as nutrient cycling and the larval settlement of various benthic organisms, but benthic-pelagic coupling is also important in the life cycles of some species traditionally considered to be holoplanktonic. The results of the present study have revealed that seagrass presence has a significant influence on the retention of benthic resting stages of plankton. As near-shore seagrass beds dete- riorate and disappear from some areas, copepod resting eggs that would otherwise be held in place could be washed away or hatch. The loss of this egg reservoir could potentially alter the population dynamics of local coastal zooplankton or lead to the complete disappearance of planktonic species that rely on benthic recruitment to remain in an area. Such changes at the base of coastal food webs could have significant effects on both higher and lower trophic levels, so it is important to further assess what roles seagrass beds play in the population dynamics of local planktonic organisms.

\section{LITERATURE CITED}

Agawin NSR, Duarte CM (2002) Evidence of direct particle trapping by a tropical seagrass meadow. Estuaries 25(6A): 1205-1209

> Asmus H, Asmus R (2000) Material exchange and food web of seagrass beds in the Sylt-Rømø Bight: How significant are community changes at the ecosystem level? Helgol Mar Res 54:137-150

Baier CT, Purcell JE (1997) Trophic interactions of chaetognaths, larval fish, and zooplankton in the South Atlantic Bight. Mar Ecol Prog Ser 146:43-97

Ban S, Minoda T (1992) Hatching of diapause eggs of Eurytemora affinis (Copepoda: Calanoida) collected from lakebottom sediments. J Crustac Biol 12:51-56

Bell SS, Robbins BD, Jensen SL (1999) Gap dynamics in a seagrass landscape. Ecosystems 2:493-504

Boström C, Bonsdorff E (2000) Zoobenthic community establishment and habitat complexity - the importance of seagrass shoot-density, morphology and physical disturbance for faunal recruitment. Mar Ecol Prog Ser 205:123-138

- Chen F, Marcus NH (1997) Subitaneous, diapause, and delayed-hatching eggs of planktonic copepods from the northern Gulf of Mexico: morphology and hatching success. Mar Biol 127:587-597

de Boer WF (2007) Seagrass-sediment interactions, positive feedbacks and critical thresholds for occurrence: a review. Hydrobiologia 591:5-24

De Stasio BT Jr (1990) The role of dormancy and emergence patterns in the dynamics of a freshwater zooplankton community. Limnol Oceanogr 35:1079-1090

Di Carlo G, Kenworthy WJ (2008) Evaluation of aboveground and belowground biomass recovery in physically disturbed seagrass beds. Oecologia 158:285-298

> Duarte CM, Benavent E, Sánchez Md C (1999) The microcosm of particles within seagrass Posidonia oceanica canopies. Mar Ecol Prog Ser 181:289-295

Eiane K, Aksnes DL, Ohman MD, Wood S, Martinussen MB (2002) Stage-specific mortality of Calanus spp. under different predation regimes. Limnol Oceanogr 47: $636-645$

Engel M, Hirche HJ (2004) Seasonal variability and interspecific differences in hatching of calanoid copepod resting eggs from sediments of the German Bight (North Sea). J Plankton Res 26:1083-1093

> Fisher R (2003) Spatial and temporal variations in nematode assemblages in tropical seagrass sediments. Hydrobiologia 493:43-63

> Gacia E, Duarte CM (2001) Sediment retention by a Mediterranean Posidonia oceanica meadow: the balance between 
deposition and resuspension. Estuar Coast Shelf Sci 52: 505-514

Gacia E, Granata TC, Duarte CM (1999) An approach to measurement of particle flux and sediment retention within seagrass (Posidonia oceanica) meadows. Aquat Bot 65: 255-268

> Gambi MC, Nowell AM, Jumars PA (1990) Flume observations on flow dynamics in Zostera marina (eelgrass) beds. Mar Ecol Prog Ser 61:159-169

Granata TC, Serra T, Colomer J, Casamitjana X, Duarte CM, Gacia E (2001) Flow and particle distributions in a nearshore seagrass meadow before and after a storm. Mar Ecol Prog Ser 218:95-106

Green EP, Short FT (2003) World atlas of seagrasses. University of California Press, Cambridge, UK

Grice GD, Marcus NH (1981) Dormant eggs of marine copepods. Oceanogr Mar Biol Annu Rev 19:125-140

Hairston NG Jr (1996) Zooplankton egg banks as biotic reservoirs in changing environments. Limnol Oceanogr 41: 1087-1092

> Hairston NG Jr, Kearns CM (2002) Temporal dispersal: ecological and evolutionary aspects of zooplankton egg banks and the role of sediment mixing. Integr Comp Biol 42: 481-491

Hall CJ, Burns CW (2001) Hatching of Boeckella hamata (Copepoda: Calanoida) resting eggs from sediments of a tidally influenced lake. N Z J Mar Freshw Res 35:235-238

> Hammerstrom KK, Kenworthy WJ, Fonseca MS, Whitfield PE (2006) Seed bank, biomass, and productivity of Halophila decipiens, a deep water seagrass on the west Florida continental shelf. Aquat Bot 84:110-120

> Hoover RS, Hoover D, Miller M, Landry MR, DeCarlo EH, Mackenzie FT (2006) Zooplankton response to storm runoff in a tropical estuary: bottom-up and top-down controls. Mar Ecol Prog Ser 318:187-201

Iverson RL, Bittaker HF (1986) Seagrass distribution and abundance in Eastern Gulf of Mexico coastal waters. Estuar Coast Shelf Sci 22:577-602

> Joyce LB (2004) Dinoflagellate cysts in recent marine sediments from Scapa Flow, Orkney, Scotland. Bot Mar 47: $173-183$

Katajisto T (2004) Effects of anoxia and hypoxia on the dormancy and survival of subitaneous eggs of Acartia bifilosa (Copepoda: Calanoida). Mar Biol 145:751-757

Katajisto T, Viitasalo M, Koski M (1998) Seasonal occurrence and hatching of calanoid eggs in sediments of the northern Baltic Sea. Mar Ecol Prog Ser 163:133-143

Kiørboe T (1997) Population regulation and role of mesozooplankton in shaping marine pelagic food webs. Hydrobiologia 363:13-27

Lass S, Spaak P (2003) Chemically induced anti-predator defences in plankton: a review. Hydrobiologia 491: 221-239

Lawrence D, Dagg MJ, Liu H, Cummings SR, Ortner PB, Kelble C (2004) Wind events and benthic-pelagic coupling in a shallow subtropical bay in Florida. Mar Ecol Prog Ser 266:1-13

Lee KS, Park JI, Kim YK, Park SR, Kim JH (2007) Recolonization of Zostera marina following destruction caused by a red tide algal bloom: the role of new shoot recruitment from seed banks. Mar Ecol Prog Ser 342:105-115

Lindley JA (1990) Distribution of overwintering calanoid copepod eggs in sea-bed sediments around southern Britain. Mar Biol 104:209-217

Marbà N, Duarte CM (1995) Coupling of seagrass (Cymodocea nodosa) patch dynamics to subaqueous dune migration. J Ecol 83:381-389
Marcus NH (1984) Recruitment of copepod nauplii into the plankton: importance of diapause eggs and benthic processes. Mar Ecol Prog Ser 15:47-54

Marcus NH (1989) Abundance in bottom sediments and hatching requirements of eggs of Centropages hamatus (Copepoda: Calanoida) from the Alligator Harbor region, Florida. Biol Bull 176:142-146

Marcus NH (1996) Ecological and evolutionary significance of resting eggs in marine copepods: past, present, and future studies. Hydrobiologia 320:141-152

Marcus NH, Boero F (1998) Minireview: the importance of benthic-pelagic coupling and the forgotten role of life cycles in coastal aquatic systems. Limnol Oceanogr 43: $763-768$

Marcus NH, Fuller CM (1986) Subitaneous and diapause eggs of Labidocera aestiva Wheeler (Copepoda: Calanoida): differences in fall velocity and density. J Exp Mar Biol Ecol 99:247-256

Marcus NH, Fuller CM (1989) Distribution and abundance of eggs of Labidocera aestiva (Copepoda: Calanoida) in the bottom sediments of Buzzards Bay, Massachusetts, USA. Mar Biol 100:319-326

> Marcus NH, Lutz RV (1994) Effects of anoxia on the viability of subitaneous eggs of planktonic copepods. Mar Biol 121: $83-87$

Marcus NH, Lutz RV (1998) Longevity of subitaneous and diapause eggs of Centropages hamatus (Copepoda: Calanoida) from the northern Gulf of Mexico. Mar Biol 131: 249-257

> Marcus NH, Lutz RV, Chanton JP (1997) Impact of anoxia and sulfide on the viability of eggs of three planktonic copepods. Mar Ecol Prog Ser 146:291-295

McGlathery KJ, Sundbäck K, Anderson IC (2007) Eutrophication in shallow coastal bays and lagoons: the role of plants in the coastal filter. Mar Ecol Prog Ser 348:1-18

McQuoid MR, Hobson LA (1996) Diatom resting stages. J Phycol 32:889-902

> Nepf HM, Mugnier CG, Zavistoski RA (1997) The effects of vegetation on longitudinal dispersion. Estuar Coast Shelf Sci 44:675-684

Onbé T (1978) Sugar floatation method for sorting the resting eggs of marine cladocerans and copepods from seabottom sediment. Bull Jpn Soc Sci Fish 44:1411

Pringault O, Duran R, Jacquet S, Torréton JP (2008) Temporal variations of microbial activity and diversity in marine tropical sediments (New Caledonia Lagoon). Microb Ecol 55:247-258

Roman MR, Dam HG, Gauzens AL, Urban-Rich J, Foley DG, Dickey TD (1995) Zooplankton variability on the equator at $140 \infty \mathrm{W}$ during the JGOFS EqPac study. Deep-Sea Res II 42:673-693

Scheef LP (2010) The effects of seagrass on the benthic distribution of copepod resting eggs. PhD dissertation, Florida State University, Tallahassee

Thamdrup B, Hansen JW, Jørgensen BB (1998) Temperature dependence of aerobic respiration in coastal sediment. FEMS Microbiol Ecol 25:189-200

Tsuda A, Takeda S, Saito H, Nishioka J and others (2007) Evidence for the grazing hypothesis: Grazing reduces phytoplankton responses of the HNLC ecosystem iron enrichment in the western subarctic Pacific (SEEDS II). J Oceanogr 63:983-994

Turner JT (2004) The importance of small planktonic copepods and their roles in pelagic marine food webs. Zool Stud 43:255-266

Uye S (1985) Resting egg production as a life history strategy of marine planktonic copepods. Bull Mar Sci 37:440-449 
Uye S, Kasahara S, Onbé T (1979) Calanoid copepod eggs in sea-bottom muds. IV. Effects of some environmental factors on the hatching of resting eggs. Mar Biol 51:151-156

van der Heide T, van Nes EH, Geerling GW, Smolders AJP, Bouma TJ, van Katwijk MM (2007) Positive feedbacks in seagrass ecosystems: implications for success in conservation and restoration. Ecosystems 10:1311-1322

van Keulen M, Borowitzka MA (2003) Seasonal variability in sediment distribution along an exposure gradient in a sea-

Editorial responsibility: William Peterson,

Newport, Oregon, USA grass meadow in Shoalwater Bay, Western Australia. Estuar Coast Shelf Sci 57:587-592

Viitasalo M (1992) Calanoid resting eggs in the Baltic Sea: implications for the population dynamics of Acartia bifilosa (Copepoda). Mar Biol 114:397-405

Yin K, Harrison PJ, Goldblatt RH, Beamish RJ (1996) Spring bloom in the central Strait of Georgia: interactions of river discharge, winds, and grazing. Mar Ecol Prog Ser 138: $255-263$

Submitted: November 10, 2009; Accepted: March 7, 2010 Proofs received from author(s): May 7, 2010 